\title{
Dynamic strength of the quadriceps muscle and sports activity
}

\author{
Thomas Hahn, Anders Foldspang, Thorsten Ingemann-Hansen
}

\begin{abstract}
The study objectives were to examine the dynamic strength of the quadriceps muscle in athletes, and investigate its association with participation in sport. The study comprised 168 active competitive non-pregnant athletes, aged 14-24 years. The dynamic strength of their quadriceps muscle was measured, and they answered a questionnaire about sports activity and occupation. The dynamic strength of the quadriceps muscle was significantly higher in men than in women, and was positively associated with body weight, years of jogging, years of soccer, and weekly hours of basketball. In conclusion, the dynamic strength of the quadriceps muscle seems to be associated with sports activity. The results suggest sport specific adaptation, which may reflect high levels of running and jumping activity.

(Br f Sports Med 1999;33:117-120)
\end{abstract}

Keywords: soccer; jogging; basketball; quadriceps muscle

The dynamic strength of the quadriceps muscle is important for the stability and movement of the human body and thus for sports activity. Reduced dynamic strength of the quadriceps muscle has been associated with knee injury in athletes, ${ }^{12}$ and strengthening exercise of the quadriceps muscle seems to be important for the prevention and rehabilitation of knee injury. ${ }^{3-6}$

Several studies have investigated the dy-

Sports Clinic, Department of Rheumatology, Aarhus University Hospital,

Aarhus, Denmark

T Hahn

Institute of

Epidemiology and

Social Medicine,

Aarhus University

A Foldspang

Department of Sports

Science, Aarhus

University

$\mathrm{T}$ Ingemann-Hansen

Correspondence to:

Dr T Hahn, Sports Clinic, Department of

Rheumatology, Research

Unit, Building 1B, 2nd

Floor, Nørrebrogade 44,

DK-8000 Aarhus C,

Denmark.

Accepted for publication 23 November 1998 namic strength of the quadriceps muscle in athletes, ${ }^{6-13}$ but few studies have compared the results for athletes participating in different types of sport. ${ }^{10-13}$ Furthermore, published studies are generally small and include only elite athletes or other selective groups, which only give limited information on quadriceps strength and sports activity in general. Epidemiological studies of the dynamic strength of the quadriceps muscle and its potential association with different types of sports activity are

Table 1 Dynamic strength (expressed as one repetition maximum (kg)) of the quadriceps muscle by age and sex in 168 athletes, Aarhus, Denmark, 1992

\begin{tabular}{llllllll}
\hline & \multicolumn{2}{l}{ Women } & \multicolumn{5}{l}{ Men } \\
\cline { 2 - 3 } Age (years) & No & $k g$ & $S D$ & & No & $k g$ & $S D$ \\
\hline $14-15$ & 22 & 12.8 & 4.48 & & 24 & 16.4 & 3.99 \\
$16-17$ & 25 & 12.5 & 3.52 & & 24 & 17.6 & 3.40 \\
$18-20$ & 11 & 14.3 & 4.38 & & 26 & 19.1 & 4.72 \\
$21-24$ & 11 & 13.0 & 3.94 & & 25 & 20.3 & 4.45 \\
Total & 69 & 13.0 & 4.01 & & 99 & 18.4 & 4.38 \\
\hline
\end{tabular}

thus needed. These investigations may be important for the development of effective strategies for preventing knee injury and for the continuing development of sports training programmes.

The aim of this study was to examine the dynamic strength of the quadriceps muscle in athletes and to investigate potential associations with participation in sport.

\section{Methods}

The study comprised active competitive nonpregnant athletes, aged 14-24 years, who were members of one of two sports clubs in Aarhus County, Denmark. One sports club was suburban, near the city of Aarhus (204 000 inhabitants), and the other was situated in a rural area (Ebeltoft; 13338 inhabitants). ${ }^{14}$ During April to December 1992, the dynamic strength of the quadriceps muscle, body weight, and body height of 168 consecutive athletes were measured. The athletes also answered a questionnaire about sports activity and occupation within the preceding 12 months.

Table 2 Dynamic strength (expressed as one repetition maximum (1RM)) of the quadriceps muscle by type of sport played within the preceding 12 months in 168 athletes, Aarhus, Denmark, 1992

\begin{tabular}{|c|c|c|c|c|}
\hline \multirow[b]{2}{*}{ Type of sport } & \multirow{2}{*}{$\frac{\text { Athletes }}{\text { No (\%) }}$} & \multicolumn{3}{|c|}{$1 R M(\mathrm{~kg})$} \\
\hline & & Mean & $B$ & $S E(B)$ \\
\hline Soccer & $64(38)$ & 17.0 & -0.79 & 0.43 \\
\hline European team handball & $12(7)$ & 15.4 & -0.52 & 0.50 \\
\hline Basketball & $80(48)$ & 16.2 & 0.19 & 0.49 \\
\hline Badminton & $42(25)$ & 15.3 & -0.51 & 0.55 \\
\hline Tennis & $27(16)$ & 17.4 & 0.37 & 0.67 \\
\hline Competitive gymnastics & $14(8)$ & 13.1 & -1.34 & 0.89 \\
\hline Swimming & $16(10)$ & 14.7 & $1.35^{\star}$ & 0.58 \\
\hline Jogging & $46(27)$ & 17.0 & -0.20 & 0.48 \\
\hline
\end{tabular}

As the athletes participate in more than one type of sport the numbers add up to more than 168. Sex and age corrected linear regression estimates $(\mathrm{B}$, slope of the regression line and standard error, $\mathrm{SE}$ ) of specific types of sport $v$ others are given. ${ }^{\star} \mathrm{p}<0.05$.

Table 3 Dynamic strength (expressed as one repetition maximum (1RM)) of the quadriceps muscle by the mean number of hours of sport per week within the preceding 12 months in 168 athletes, Aarhus, Denmark, 1992

\begin{tabular}{|c|c|c|c|c|}
\hline \multirow[b]{2}{*}{ Type of sport } & \multicolumn{2}{|c|}{$\begin{array}{l}\text { Hours of sport per } \\
\text { week }\end{array}$} & \multicolumn{2}{|c|}{$1 R M(k g)$} \\
\hline & Mean & Range & $B$ & $S E(B)$ \\
\hline Soccer & 3.63 & $0-8$ & 0.13 & 0.12 \\
\hline European team handball & 2.09 & $1-4$ & 0.16 & 0.16 \\
\hline Basketball & 5.55 & $1-12$ & $0.26^{\star}$ & 0.12 \\
\hline Badminton & 2.56 & $0-4$ & -0.60 & 0.30 \\
\hline Tennis & 2.00 & $0-8$ & 0.47 & 0.40 \\
\hline Competitive gymnastics & 4.38 & $1-10$ & -0.10 & 0.33 \\
\hline Swimming & 1.67 & $0-5$ & -0.10 & 0.09 \\
\hline Jogging & 1.51 & $0-5$ & 0.25 & 0.37 \\
\hline
\end{tabular}

Sex and age corrected linear regression estimates $(\mathrm{B}$, slope of the regression line and standard error, SE) per hour of sport per week are given. ${ }^{\star} \mathrm{p}<0.05$. 
Table 4 Dynamic strength (expressed as one repetition maximum (1RM)) of the quadriceps muscle by years in sport in 168 athletes, Aarhus, Denmark, 1992

\begin{tabular}{lcccccc}
\hline & \multicolumn{2}{c}{ Years in sport } & & \multicolumn{2}{l}{$1 R M(\mathrm{~kg})$} \\
\cline { 2 - 3 } \cline { 6 - 7 } Type of sport & Mean & Range & & & & \multicolumn{2}{c}{$S E(B)$} \\
\hline Soccer & 6.72 & $1-16$ & & 0.08 & 0.07 \\
European team handball & 3.26 & $0-13$ & & 0.06 & 0.08 \\
Basketball & 5.37 & $0-15$ & & 0.15 & 0.11 \\
Badminton & 4.62 & $1-16$ & & $-0.24^{\star}$ & 0.11 \\
Tennis & 2.67 & $1-10$ & & 0.23 & 0.23 \\
Competitive gymnastics & 4.46 & $1-15$ & & 0.00 & 0.13 \\
Swimming & 3.35 & $0-14$ & & 0.00 & 0.10 \\
Jogging & 3.69 & $1-15$ & & $0.46^{\star}$ & 0.18 \\
\hline
\end{tabular}

Sex and age corrected linear regression estimates (B, slope of the regression line and standard error, SE) per year of sport are given. ${ }^{\star} \mathrm{p}<0.01$

Table 5 Significant multiple regression estimates (B, slope of the regression line, and standard error, $S E$ ) predicting the dynamic strength (expressed as one repetition maximum (1RM)) of the quadriceps muscle in 168 athletes, Aarhus, Denmark, 1992

\begin{tabular}{lll}
\hline & \multicolumn{2}{l}{$1 R M^{\star}(\mathrm{kg})$} \\
\cline { 2 - 3 } Predictor & $B$ & $S E(B)$ \\
\hline Female gender & $-2.96^{\mathrm{c}}$ & 0.75 \\
Body weight (kg) & $0.18^{\mathrm{c}}$ & 0.03 \\
Years of jogging & $0.44^{\mathrm{b}}$ & 0.17 \\
Years of soccer & $0.15^{\mathrm{a}}$ & 0.07 \\
Hours of basketball per week $\dagger$ & $0.31^{\mathrm{b}}$ & 0.12 \\
\hline
\end{tabular}

$\star$ Overall $\mathrm{F}=27.25$, df 5,145, $\mathrm{p}<0.001 ;$ adjusted $r^{2}=0.47$. †Mean within the preceding 12 months. ${ }^{a} \mathrm{p}<0.05$. ${ }^{b} \mathrm{p}<0.01$. ${ }^{c} \mathrm{p}<0.001$.

A simple method of measuring the dynamic strength of the quadriceps muscle has been developed by De Lorme..$^{15}$ The method shows both high reproducibility ${ }^{6}$ and high correlation with other kinds of strength assessments. ${ }^{12}$ Its simplicity makes it suitable for population based studies. It consists of determining the maximal load a person can lift once (one repetition maximum $(1 \mathrm{RM})) .{ }^{56}$ The load is placed on a special weight shoe on the athlete's foot. While sitting on a bench, the athlete extends the knee from $90^{\circ}$ to $0^{\circ}$, and the maximal load $(\mathrm{kg})$ is registered.

In this study, $1 \mathrm{RM}$ data were approximately normally distributed. Test results showed no significant difference between the left and right quadriceps muscle. The mean of the two body

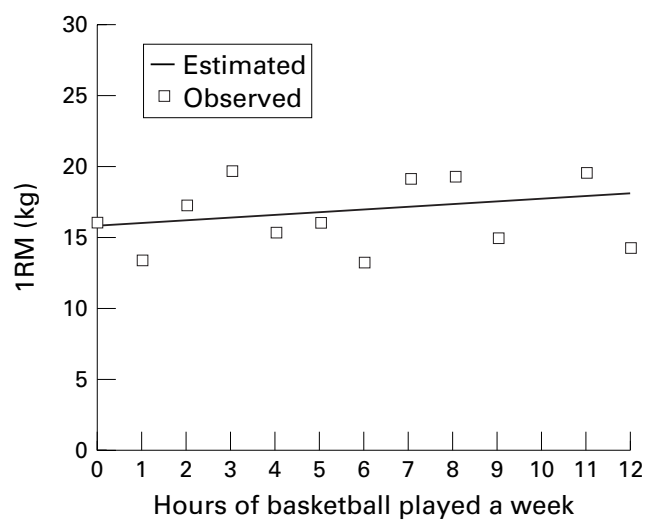

Figure 1 Observed and estimated mean dynamic strength of the quadriceps muscle by hours of basketball played a week in 168 athletes in Aarhus, Denmark, 1992. The dynamic strength is estimated by linear regression and expressed as one repetition maximum (1RM) in $\mathrm{kg}$. Model: $1 R M=15.92+(0.18 \times$ hours of basketball per week $)$; $p>0.20$. sides was used for statistical analyses, which included Pearson's $\chi^{2}$ test, Student's $t$ test, and multiple linear regression, performed by a combination of forward selection and backward elimination. ${ }^{16}$ Outliers $(1.8 \%$ of the $1 \mathrm{RM}$ data) were removed to improve estimates of means. Multiple linear regressions included age, sex, body weight, body height, sports club, sport (type and number of types; years and mean numbers of weekly hours of participation within the preceding 12 months), and occupation (years; mean numbers of weekly and daily hours of standing, walking, and sitting occupational work within the preceding 12 months). $p$ $=0.05$ was used as a general level of significance.

The project was approved by the Regional Committee of Ethics of Medical Science, Aarhus, Denmark, and by the National Registry Inspectorate.

\section{Results}

SPORTS PARTICIPATION AND OCCUPATION

The mean (SD) duration of sports participation was 10 (3.7) years and the mean weekly amount of sports participation was eight hours (median seven hours, range 0-32 hours). The mean duration of occupational work was two years (median one year, range $0-13$ years) and the mean weekly amount of occupational work was 13 hours (median six hours, range 0-60 hours).

DYNAMIC STRENGTH OF THE QUADRICEPS MUSCLE, BODY HEIGHT, AND BODY WEIGHT The mean $1 \mathrm{RM}$ was $16.2 \mathrm{~kg}$, with no significant difference between the left and right quadriceps muscle. The value was higher in men than in women (mean difference $5.4 \mathrm{~kg}$, $\mathrm{p}<0.001$ ) (table 1). Mean female body height was $168 \mathrm{~cm}$ (range 156-190 cm), and mean male body height was $179 \mathrm{~cm}$ (range 162-193 $\mathrm{cm}$ ). Mean body weight was $60 \mathrm{~kg}$ (range 45-88 kg) and $71 \mathrm{~kg}$ (range 45-102 kg) in women and men respectively $(p<0.001)$.

DYNAMIC STRENGTH OF THE QUADRICEPS MUSCLE AND SPORTS ACTIVITY

In bivariate analyses, $1 \mathrm{RM}$ was found to be positively associated with age, body weight, participation in swimming within the preceding 12 months, years of jogging, and weekly hours of basketball played within the preceding 12 months, but negatively associated with years of badminton played (tables 2-4).

In multiple linear regressions, 1RM was positively associated with body weight and years of jogging, years of soccer, and weekly hours of basketball within the preceding 12 months (table 5, figs 1 and 2).

\section{Discussion}

The dynamic strength of the quadriceps muscle was positively associated with years of jogging, years of soccer, and weekly hours of basketball. As expected, we also found the dynamic strength of the quadriceps muscle to be higher in men than in women and positively associated with body weight. Mean 1RM was $16.2 \mathrm{~kg}$, which is lower than found in 

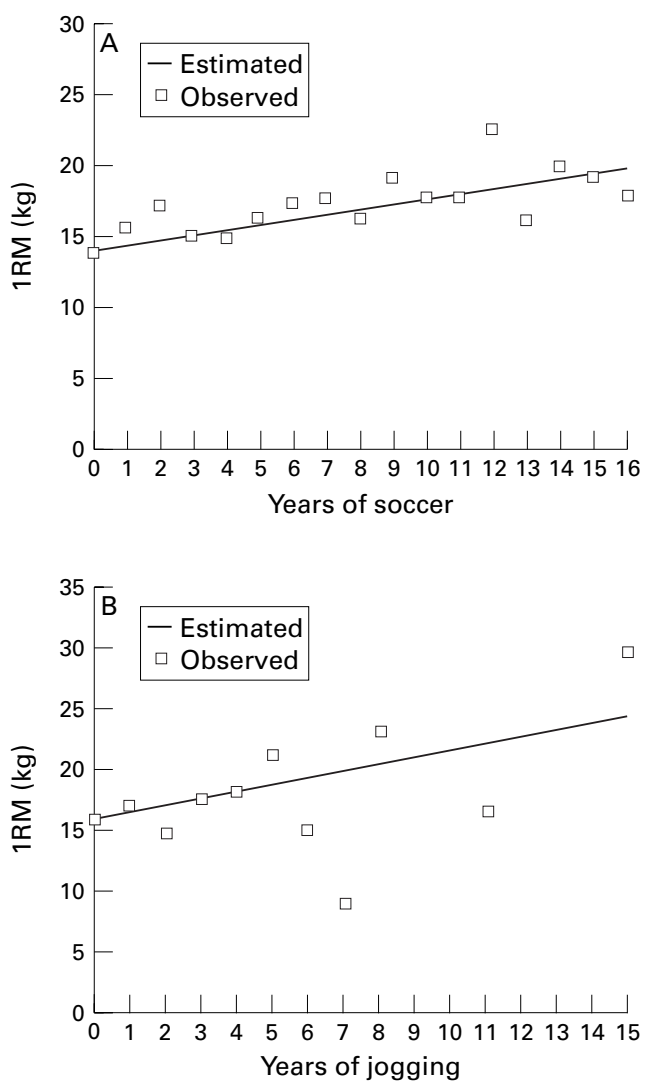

Figure 2 Observed and estimated mean dynamic strength of the quadriceps muscle by years of sports participation in 168 athletes Aarhus, Denmark, 1992. Dynamic strength is estimated by linear regression and expressed as one repetition maximum (1RM) in kg. Models: $1 R M=13.94$ $+(0.35 \times$ years of soccer $), p<0.001 ; 1 R M=15.78+$ $(0.57 \times$ years of jogging), $p<0.02$.

previously published studies $(23.6-27 \mathrm{~kg}) .^{56}$ The latter studies, however, looked at only male soccer players with a mean age of 25 years, in contrast with the variety of sports played by the younger athletes in the present paper. In bivariate analyses, the dynamic strength of the quadriceps muscle was positively associated with age. However, after multivariate analysis, this association disappeared, which reflects confounding from the associations found with years of sports participation. Surprisingly, there was no significant difference between the dynamic strength of the left and right quadriceps muscle. This, however, agrees with previous studies ${ }^{17}{ }^{18}$ and may reflect inadequate sensitivity of the test to discriminate between minor differences in dynamic quadriceps strength.

As none of the types of sport considered here are so called "maximal strength sports", ${ }^{19}$ - for example, weightlifting, wrestling and rowing, we did not expect to find any association with the type of sport as such. However, considering the adaptive changes that occur in muscles of exercising athletes, we expected to find an association with number of years and weekly hours of sports participation at large. These expectations were partly confirmed by the positive association with weekly hours of basketball (table 5 and fig 1 ). The result is in accordance with the fact that basketball includes a lot of running and jumping, which involve large sustained amounts of quadriceps muscle activity. Basketball players are, in general, taller than other athletes, and the results may reflect an association between body height and the dynamic strength of the quadriceps muscle. However, the association between dynamic strength of the quadriceps muscle and weekly hours of basketball was corrected for body height. Moreover, the basketball players in this study were not significantly taller than the other athletes.

The study may have been biased by "healthy athlete selection" - that is, athletes with knee problems caused by reduced strength of the quadriceps muscle may have changed to other types of sport or may have stopped participating in sport as such. However, there was no association between prior cessation of a sport because of knee symptoms and the present type of sport played. The present results may also have been biased by positive selection resulting from the athletes' initial choice of sport - that is, athletes may chose to participate in a power sport because they have high dynamic strength of the quadriceps muscle. As jogging and soccer mainly represent endurance types of sport, the positive associations between dynamic strength of the quadriceps muscle and years of jogging or soccer seem to reflect exercise induced adaptation rather than selection bias. Moreover, the fact that soccer includes a lot of running $^{20}$ supports the notion of a running induced adaptation of the dynamic strength of the quadriceps muscle. The present results furthermore suggest that jogging may be used to increase the dynamic strength of the quadriceps muscle, especially as a supplement to basketball and soccer training, for which the dynamic strength of the quadriceps muscle seems to be of particular importance. These associations between dynamic strength of the quadriceps muscle and different types of sports activity have not been documented previously, and should be further investigated.

In conclusion, the dynamic strength of the quadriceps muscle seems to be associated with sports activity. The results suggest a sport specific adaptation of the muscle, which may reflect running and jumping activity.

This study was supported by The Prevention Council of Aarhus County, Aarhus, Denmark, and The Ministry of Health Foundation for Health Research and Development, Copenhagen, Denmark (grant No 289-1993).

1 Ekstrand J, Gillquist J. The avoidability of soccer injuries. Int 7 Sports Med 1983;4:124-8.

2 Thomeé R, Renström P, Karlsson J, et al. Patellofemoral Thomee R, Renstrom P, Karlsson J, et al. Patellofemoral
pain syndrome in young women. II. Muscle function in patients and healthy controls. Scand $\mathcal{F}$ Med Sci Sports 1995; 5:245-51

3 Kannus P, Niittymaki S. Which factors predict outcome in the nonoperative treatment of patellofemoral pain syndrome? A prospective follow-up study. Med Sci Sports Exerc 1994;26:289-96.

4 Grimby G. Clinical aspects of strength and power training. In: Komi PV, ed. Strength and power in sport. Oxford: Blackwell Scientific Publications, 1991;338-54.

5 Ingemann-Hansen T, Halkjær-Kristensen J. Progressive resistance exercise training of the hypotrophic quadriceps tion as well as the influence of duration of effort. Scand $\mathcal{F}$ tion as well as the influence
Rehabil Med 1983;15:29-35.

6 Ingemann-Hansen T, Halkjær-Kristensen J. Effect of low-load dynamic training on the quadriceps muscle in man. In: Morecki A, Fidelus K, Kędzior K, et al, eds. Biomechanics VII-B. Warszawa: Polish Scientific Publishers,
1981;398-403. 
7 Öberg B, Ekstrand J, Möller M, et al. Muscle strength and flexibility in different positions of soccer players. Int f Sports

8 Russell KW, Quinney HA, Hazlett CB, et al. Knee muscle strength in elite male gymnasts. F Orthop Sports Phys Ther $1995 ; 22: 10-17$

9 Ingemann-Hansen T, Halkjær-Kristensen J. Lean and fat component of the human thigh. The effects of immobilization in plaster and subsequent physical training. Scand $\mathcal{F}$ Rehabil Med 1977;9:67-72.

10 Read MT, Bellamy MJ. Comparison of hamstring/ quadriceps isokinetic strength ratios and power in tennis, squash and track athletes. Br F Sports Med 1990;24:178-82.

11 Thomas TR, Zebas CJ, Bahrke MS, et al. Physiological and psychological correlates of success in track and field athletes. Br F Sports Med 1983;17:102-9.

12 Abernethy P, Wilson G, Logan P. Strength and power assessment. Issues, controversies and challenges. Sports Med 1995;19:401-17.

13 Brown SL, Wilkinson JG. Characteristics of national, divisional, and club male alpine ski racers. Med Sci Sports Exerc 1983;15:491-5.
14 Denmark Statistics. Statistical yearbook 1993. Aarhus, Denmark: Danmarks Statistik, 1993.

15 De Lorme TL. Restoration of muscle power by heavyresistance exercises. F Bone foint Surg 1945;27:64566.

16 Armitage P, Berry G. Statistical methods in medical research. London, Boston, Melbourne: Blackwell Scientific Publications, 1971.

17 Halkjær-Kristensen J, Ingemann-Hansen T. Wasting of the human quadriceps muscle after knee ligament injuries. I. Anthropometrical consequences. Scand 7 Rehabil Med Suppl 1985;13:5-11.

18 Halkjær-Kristensen J, Ingemann-Hansen T. Wasting of the human quadriceps muscle after knee ligament injuries. IV. Dynamic and static muscle function. Scand $\mathcal{F}$ Rehabil Med Suppl 1985;13:29-37.

19 Tittel K, Wutscherk H. Anthropometric factors. In: Komi PV, ed. Strength and power in sport. Oxford: Blackwell Scientific Publications, 1992;180-96.

20 Bangsbo J, Nørregaard L, Thorsø F. Activity profile of competition soccer. Can f Sport Sci 1991;16:110-16.

Take home message

The results suggest sport specific adaptation of the quadriceps muscle, which may reflect high levels of running and jumping activity.

\section{What is a stitch?}

Everyone is familiar with the concept of "stitch", probably best described as the "pain nibbling at his right side suddenly took a pit bull-sized chomp". Obviously, such pain is not life threatening, but can be event threatening. The gradual but inexorable increase in pain can only be relieved by ceasing whatever exercise is being undertaken at the time.

As yet, no scientific appraisal has ever been made of this problem and an "electronic" search only produced one non-peer reviewed paper on the subject. ${ }^{1}$

The main problem with a "stitch" is its highly variable and random manner of onset, although it does seem to be less frequently observed in more highly trained athletes. This produces the hypothesis that the symptoms of "stitch" are primarily due to localised muscle ischaemia with a shift of blood from the gastrointestinal tract to the exercising muscles- "starved muscle theory". However, there is no consensus as to whether the intercostal muscles or the diaphragm is being "starved".

Although there is no specific pattern of lateralisation of "stitch" pain, there is an attractive theory that combines the reduction in blood flow to a muscle group with a lactic acid overload in these muscles. This may support the theory of improved muscle blood flow with increased training and therefore a reduction in the frequency of "stitch". To date, there is no scientific evidence of any link with food intake before exercise, and, similarly, many athletes are aware that avoidance of dehydration may prevent a "stitch". However, some runners contest that a water-logged stomach from excess hydration can be a factor in "stitch". To date, most runners have a moderate fluid intake before a run, and then drink little and often during it.

Unfortunately, there can be no summary of "stitch" because there is very little information available. However, adequate fluid intake during running may well be the only solution to this event threatening problem.

GERRY HAGGERTY

1 Sharp D. Side stitch sidestep (avoiding side pains while exercising). Health 1990;4:84. 